\title{
Is Homeworking a Better Option in the Digital Era? An Empirical Research across EU Member States
}

\author{
By Daniela Predețeanu-Dragne ${ }^{1}$, Ion Tudor ${ }^{1}$, Dan Popescu ${ }^{1}$, Valentina Nicolae ${ }^{1}$
}

\begin{abstract}
The complex and also very dynamic progress of information and communication technologies (ICT) enabled workforce to become more increasingly mobile. By consequence, the companies across the world have already adapted their work arrangements, offering more and more flexibility to their employees, to name just a few examples: homeworking, outsourcing, crowdsourcing, part-time work, temporary work, flexible working time. Our scientific approach represents an in-depth analysis of the homeworking trend within the EU Member States, by factors such as country and gender. It also examines the way ICT have evolved in enterprises across all Member States and provides specific trends per country. Furthermore, the research presents a comparative study of how the ICT skills enabled by companies has evolved over the last years and improved employee's lives. The results of our approach show that work from home trends increased in all EU Member States in parallel with the development of digital skills. This development make the companies to be more competitive on the market in attracting and retaining employees. In practice, companies will be required to diversify their work programs and allow flexibility in terms of working schedules and actual location of work. Of course, at the same time, the management of each company must pay a special attention to develop the ICT skills, so that people are properly equipped to perform efficiently and ensuring that the organizational performance is maintained at highest standards.
\end{abstract}

Keywords: flexible workplace, work from home, information and communication technologies

\section{Introduction}

As globalization is becoming more widespread and progress is continually made within information and communication technologies areas, the work field is as well being impacted and is changing gradually. Thousands of worldwide companies have started to enhance their benefits packages nowadays, offering employees an environment of their choice to perform work activities, one of the most preferred option being work from home. This way, people can manage much better the demands of their professional and personal lives, but they can also be more productive (Bloom, 2014).

This study examines the notion of homeworking within the context of globalization, with an attention focused on the way enterprises are investing in building digital skills for their employees, using examples from the European Union Member States.

According to World Economic Forum's Report on the future of jobs, workforce transformations are an aspect of the present, not of the far future. The reports states that over the next four years, a set of four specific technological advances are set to dominate the work environment: high-speed mobile internet, artificial intelligence, the adoption of big data analytics at global level and cloud technology (World Economic Forum, 2018). All of these are part of ICT, as they represent the framework that enables modern 
computing. Furthermore, without these technological advancements, people would not be able to choose other locations, such as home, to work from. According to Fried \& Hansson (2013), the advantages brought by working from home outweigh the disadvantages: people do not lose time commuting, they get to choose the best environment for them, they can obtain a very clear balance between their professional and personal life, yet enhancing their productivity at the same time.

This paper illustrates the fact that the digitization of business and the progress in ICT will continue to change the nature of future jobs flexibility and will increase mobility among workforce, allowing people not only to work from a different office than the traditional one, but to easily migrate from one region to another. The authors proposed the following research objectives:

- To clarify the concepts of homeworking and present a literature review.

- To present the correlation between ICT and homeworking trends within the European Union.

\section{Research Methodology}

In order to analyze the trends of homeworking and ICT in the European Union, a comparative analysis was performed by the authors by looking at factors such as: crosscountry tendencies and gender. For data examination, various reports from the Eurostat database have mainly been used.

\section{Theoretical Underpinnings}

Cambridge Dictionary defines work at home as a "workplace used to describe arrangements in which employees work in their own homes, rather than an office". To further enhance the understanding of the concept and its connection to the development of ICT, we can also add that it refers to the ability to perform core job activities from home, using information and communication technologies (Eurofound, 2015).

Some of the factors which enable this type of job flexibility are today's dynamic economic conditions and the availability of smarter technology (Timsal \& Awais, 2016). Many companies have adopted work from home programs for their employees with the clear intent to improve productivity and obtain a better organizational performance. At the same time they did this to consolidate their competitive advantage on the market, considering that there is a high interest today in workers looking for this flexibility which will allow them a much better work-life balance (Crosbie \& Moore, 2009). Offering this alternative to their employees, companies can hire talents from anywhere across the globe, they can better retain talent and ensure commitment among the workforce. Furthermore, companies can obtain savings by reducing office-related costs. From 2005 to 2011, work from home increased with $73 \%$ in the USA (Fried \& Hansson, 2013).

The research made my McCrindle (2013) also confirms that employees are starting to benefit more and more from flexible work arrangements. According to their study conducted on 250 respondents, the main reason people opt to work from home is having flexibility to handle other things $(45 \%)$, and this is followed by other grounds, such as improved work-life balance (25\%), working without distractions $(15 \%)$, being 
able to take care of children $(12 \%)$.

While working away from the traditional office can many times enable a better job performance and professional satisfaction, there are factors that need to be considered by companies when offering this alternative to their employees. Nickson \& Siddons (2004) proposed a number of aspects that need to be considered when implementing homeworking: employees need to have the right technology, logistics and support, they need to have remote worker skills to be able to be efficient in a virtual environment, there have to be clear processes and procedures established by the company in order to mitigate any potential business interruptions.

According to the study "ICT for Work: Digital skills in the workplace" launched by the European Commission in 2016, digitization is one of the most important drivers behind the transformation of the labor market and on how the people work today and it is going to be even more impactful in the future. The study also raises awareness on the importance of creating campaigns to improve people's digital skills, as these improve organizational performance and bring efficiency as well. ICT skills can vary from basic to highly advanced ones, from knowing how to process word documents, presentations, build and maintain databases, to web navigation, e-mail management, computer-related storage devices and computer security knowledge.

A research carried out by OECD in 2016 entitled "Skills for a digital world", centered around the skills required for the digital economy identified three main types of digital skills:

1. ICT generic skills refer to basic knowledge in the domain, used in the daily work, for example using emails and certain software to perform core job activities and knowing how to look for information on the Internet.

2. ICT specialist skills refer to a more advanced knowledge such as software programming, application development and network management.

3. ICT complimentary skills involve the ability to carry out tasks in a technology-rich environment.

The study also highlights that there is actually a high and diverse number of occupations that require ICT skills knowledge, not just information and communication managers, database and network professionals or software and applications developers and analysists, but also legal professionals, education teachers, librarians and sales agents.

Considering the constant progress of technologies, the nature of jobs is changing as well. Due to the fact that automation is reducing the full-time workforce across various domains and businesses, many enterprises are preparing new types of roles and are planning to expand the use of contractors for task-specialized work by utilizing work flexibility and hiring remote workers. They are consequently aiming for decentralization of operations and hiring staff beyond physical offices (World Economic Forum, 2016). The increase demand of new roles and work flexibility is a trigger for a better equipped workforce with ICT skills, from basic to advanced ones.

\section{Research Results}

In the European Union, the progress made in technological innovation, allowing instantaneous communication and the spread of multinational companies, generated a 
steady growth in the work from home programs within the Member States over the last decade. E-mails, chats, videoconferencing, web-conferencing and sharing tools now enable employees to easily work from their own home. Considering that the ability to work from home requires basic or even advanced ICT skills, from using email, to looking for information on the Internet and using particular software, an analysis was developed to observe the extent to which enterprises across the European Union are investing in delivering trainings to enhance digital skills for their staff.

\subsection{Information and Communication Technologies Usage in the European Union}

Given that a high number of today's jobs demand a good knowledge of these skills, enterprises across EU developed various training packages to improve the digital skills of their employees. In 2017 the ICS skills encompassing areas such as the use of Internet and other electronic networks by enterprises, e-commerce and e-business processes, ranged from 4\% up to 38\% in the European Union. As it can be observed in Figure.1, the percentage of enterprises that provided trainings to enhance ICS skills for their employees was at the average $21 \%$ for total countries of the European Union. The enterprises from Western and Northern Europe rank highest on the EU map in offering ICS trainings for their employees, the percentage in the majority of these countries exceeding 25\% (Finland 38\%, Belgium 35\%, Austria 31\%, and Ireland 30\%). On the other side of the spectrum, enterprises from Central and South East Europe seem to invest lower in building these skills for their employees in comparison with the ones European sub-regions (Romania 4\%, Bulgaria 9\%, Latvia 10\%, and Lithuania 11\%).

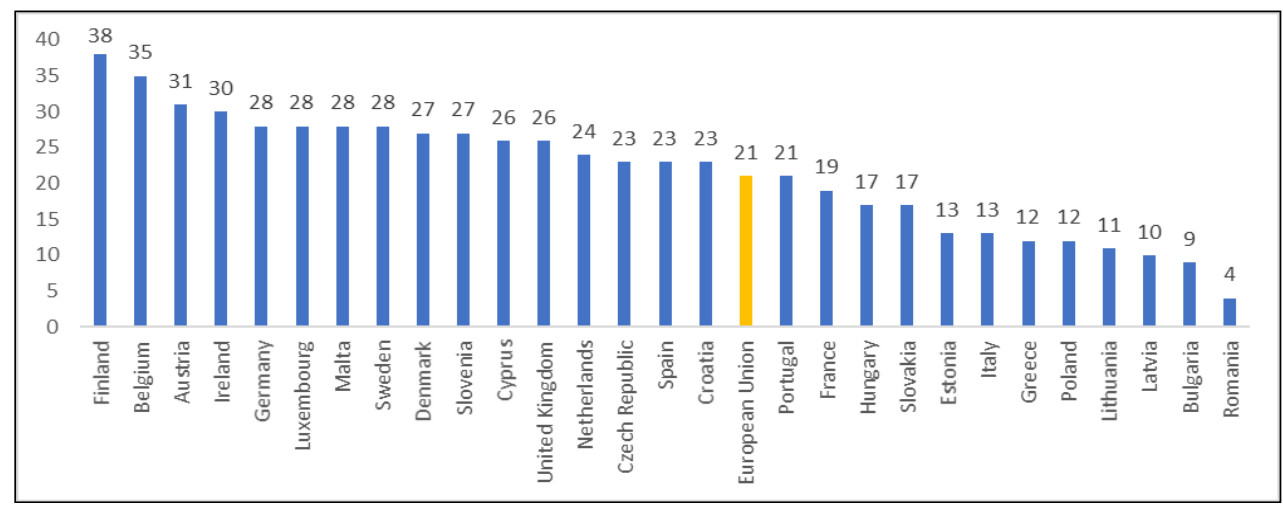

Figure 1: Percentage of enterprises that provided training to develop ICS Skills of their personnel, 2017

Source: authors, based on the data from Eurostat (bttp:/ / appsso.eurostat.ec.europa.eu/nui/show.do?dataset =isoc ske ittn2 6 lang=en)

Looking at the 2014-2017 trend across countries, it was observed that the average percentage for the entire European Union in buidling ICS skills was stable (21\%-22\%) and there were no major evolutions from one year to another per country. It was also identified that Western and Northern countries (Belgium, Austria, Ireland, Germany, Luxemburg) have the highest investments in digital skills delivery from all EU Member States, and invested similar efforts across each of the analyzed years, compared to the countries from South East Europe (Poland, Lithuania, Latvia, Bulgaria, Romania), where 
there was a rather small investment in building ICS skills (even below 10\%).

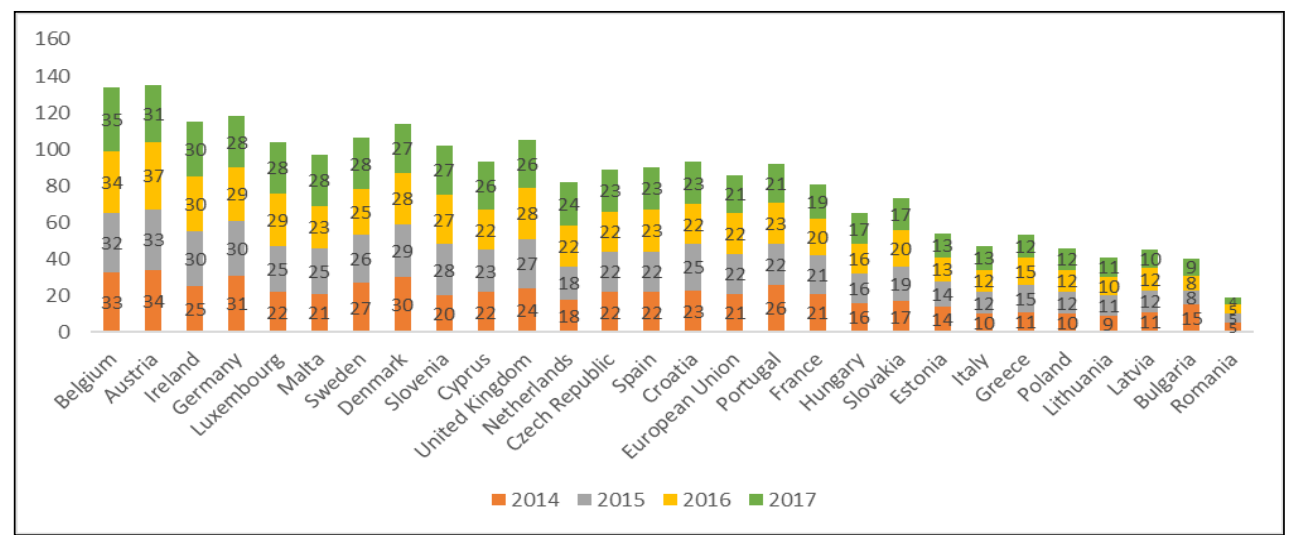

Figure 2: Percentage of enterprises that provided training to develop ICS Skills of their personnel across 20142017

Source: authors, based on the data from Eurostat (http:/ / appsso.eurostat.ec.europa.eu/nui/show.do?dataset =isoc sk dskl ierlang=en)

\subsection{The work from home trend during 2009-2017}

Figure 3 shows the work from home trend in the European Union across the last last nine years. It can be observed that there has been a slow, but firm growth in the percentage of employed adults homeworking: the trend has grown from $12.2 \%$ to $14.6 \%$, 2009 compared to 2017. Looking at the overall trend which grew over years, a slight decrease was registered in 2014, when the figure slightly dropped compared to previous year.

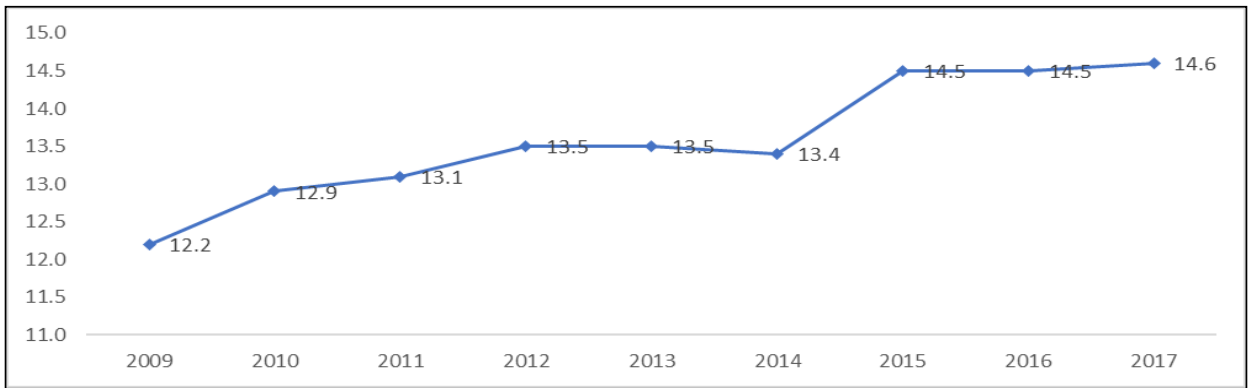

Figure 3: Total percentage of employed adults working at home in the EU, 2009 - 2017

Source: authors, based on the data from Eurostat (http:/ / appsso.eurostat.ec.europa.eu/nui/show.do?dataset =Ifst hbwahchierlang=en)

\subsection{Employed adults working at home in the EU split by gender}

In the European Union, men and women work from home in approximately similar proportions. As it can be observed in Figure 4, in 2017 there was a very small diffence in the number of men working from home (14.8\%) compared to the women $(14.5 \%)$. While there was a progress in both males and females opting to work from 
home across 2009 and 2017, there was a higher growth for women, who started from $11.9 \%$ in 2009 , versus men, who started from $12.4 \%$ same year. This can be explained by the fact that the industries with a higher incidence of homeworking are IT, engineering and science, which tend to be male-dominated occupations.

Nowadays however, both males and females can opt for a better work-life balance by integrating remote flexibility, whether they are working parents, caregivers that are looking after relatives, or job seekers that want to have time for their personal interets as well.

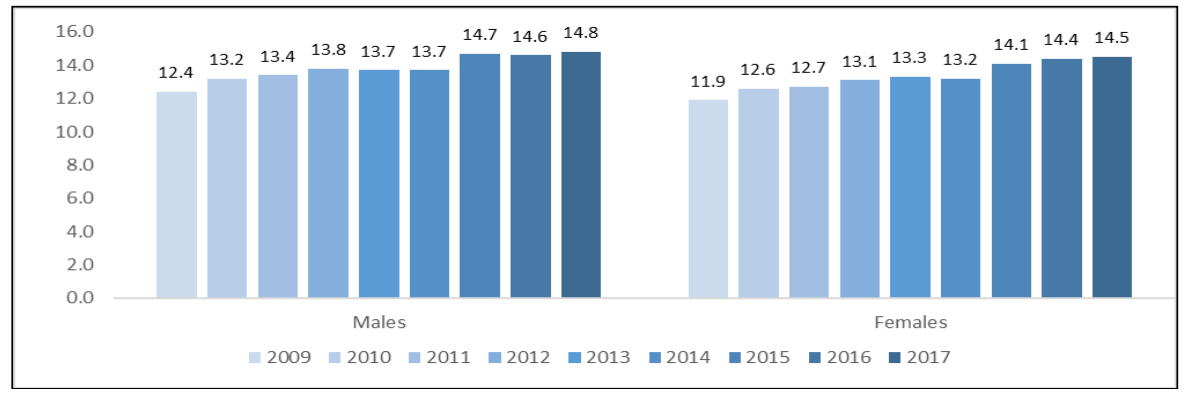

Figure 4: Total percentage of employed adults working at home in the EU by gender, 2009-2017

Source: authors, based on the data from Eurostat (bttp:/ / appsso.eurostat.ec.europa.eu/nui/show.do?dataset =lfst_bhwabchie lang=en)

\subsection{The current trend of work from home arrangements across the EU member states}

Looking at cross-country data regarding the percentage of employed adults working from home, there are big fluctuations from one country to another. The average for the European Union was $14.6 \%$ in 2017. The highest figures, above $30 \%$ were observed in Netherlands (37.7\%), Sweden (32.8\%), Denmark (31.2\%) and Luxemburg (30.6\%). South East European countries such as Romania and Bulgaria registered the lowest figures of work from home schedules, with $0.6 \%$ and respectively $1 \%$.

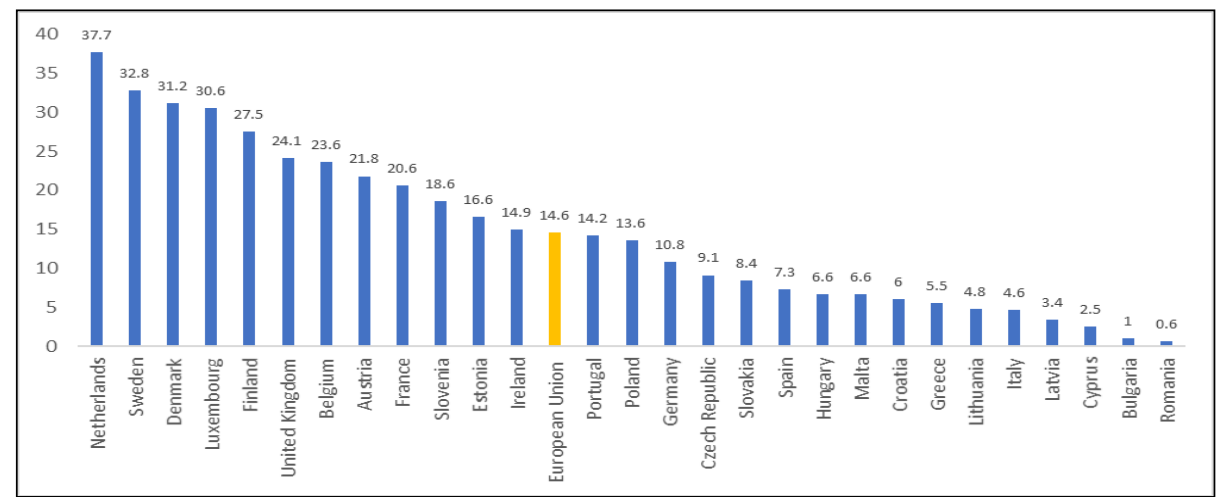

Figure 4: Percentage of employed adults working at home in the EU, 2017

Source: authors, based on the data from Eurostat (bttp:// appsso.eurostat.ec.europa.eu/nui/show.do?dataset =Ifst hbwabchie lang=en) 


\section{Identification of Key ICS Skills for Work Mobility}

Progress continues to be achieved in the development of software that offers employees all necessary tools to be able to work from a remote environment such as their home, enabling at the same time an improved user experience, as all of the innovations are available for all types of devices: laptops, phones, tablets.

Considering that many enterprises now demand ICT skills for job performance due to digitization, it is important for them to also ensure that employees are constantly updated on their skills, to be able to boost productivity. Working from home highly depends on a very good knowledge of these skills, otherwise the efficiency of people's work can be compromised. Depending on the actual work field, there are various levels of digital competency that need to be developed.

A study perfomed by the European Commision (2016) recommends a series of actions for enterprised to enable these skills. The recommendations start from emphasizing the importance of digital skills to support and improve business performance, to promoting access to technologies whithin enterprises, developing education and training systems to promote ICT core competencies, ending with including digital skills integration in wider skills strategies and desiging them as per the nature of the job and the level of the employee.

According to Eurofound's report on new forms of employment, ICT mobile work offers employees „flexibility, autonomy and empowerment” (Eurofound, 2015, p.138).

The Europe 2020 Strategy and the Digital Agenda in particular, acknowledges and proposes "to better exploit ICTs to foster innovation, economic growth and progress" (European Commission, Europe 2020 Strategy). In support of this strategy, the Commission actually created the Grand Coalition for Digital Jobs and Skills in 2013. This initiative aims at facilitating the collaboration across business and education providers, public and private actors, to improve and update people's ICT skills. Currently there are 23 Coalitions across Europe and new initiatives are scheduled yet to be lauched in 2018. All of these bring together enterprises, trainers, education and employmentministries, non-profit organizations and various parters in the overall effort of building skills at all levels of society.

The Coalition targets four key groups for skills development (European Commission, 2018) and is proposing basic or advanced skills, depending on the work area. These categories are:

1. Digital skills for all European citizens with the purpose of enabling them to be active in a digital society.

2. Digital skills for the labour force, equipping workers and job seekers across various areas with digital skills for the digital economy.

3. Digital skills for ICT proffessionals, specifically aiming at offering advanced digital skills for this category of employees in all industry sectors.

4. Digital skills in education - training teachers with digital skills, transforming teaching and building digital knowledge in education in the long perspective as well.

The workforce is therefore predicted to become increasingly mobile, as confirmed also by the research company Strategy Analytics which in their report entitled "Global Mobile Workforce Forecast Update 2016 -2022”, acknowledges that the continuous innovation 
in mobile devices and technology, designed to meet everyone's specific needs and having reasonable prices, will enable a greater number of workers to become mobile.

\section{Conclusions}

The study presents the concept of working from home and the trends in the European Union, overall, cross-country and by gender in the context of the digital era we live in today. Had it not been for the technological progress made in the last 15 years, people would not have the opportunity today to connect anytime, from any location, so easily. It is technology which brought into employee's lives the possibility of remote work, starting with fast Internet, mobile devices such as laptops and tablets, progressing to the ability to chat via instant messaging, share screen during meetings, synchronize tasks lists with the help of special software such as Basecamp, to loading and storing files with the help of cloud platforms. Being successful as a remote worker requires a specific set of skills, as being away from colleagues and supervisors presents also some opportunities. Among these skills, ICT ones are very important, as they are very much connected to the digital environment we all live in today.

The research emphasizes the fact that homeworking is a phenomenon that is increasing across all European Union Member States and that ICT skills play an important role when aiming for this job flexibility. The higher the ICT skills are, the more likely it is for employees to work from home. As per Eurostat data, the countries which invest the highest in building ICT skills for their workers are also the countries where work flexibility ranges highest on the European Union country map.

Due to the fact that in general a high variety of work fields demand these skills more and more, aquiring them is a critical factor for today's workforce. Having a workforce that is skilled appropriately helps build a better life for people and leads to improved employability, mobility and inclusion (Cedefop, 2016). Enterprises across all European Union Member States have been investing significant efforts in delivering ICT trainings for their employees, however there is an unequal distribution across countries. On average, the proportion of enterprises investing in ICT training deliveries was at 21\% across all Member States in 2017. Western and Northern Europe enterprises are investing more in building these skills, while South East Europe appears to invest less in buliding them, raking the lowest across all European Union countries. Considering that the jobs of tomorrow are thought to be incresigly mobile and relying more and more on digital skills, aquiring more than just basic ICT skills is highly recommended.

The results of this study may contribute to companies that decide to offer employees work from home schedules and want to have an understading of what are the main skills employees need to have to be able to perform at their peak from a non-traditional office as well, ensuring at the same time enhaced productivity and efficiency.

\section{References}

Bloom, N. (2014), Harvard Business Review: To Raise Productivity, Let More Employees Work from Home, Retrieved October 6, 2019, from https://hbr.org/2014/01/to-raise-productivity-let-more-employees-workfrom-home. 
Cambridge Dictionary, Retrieved March 12, 2020, from https://dictionary.cambridge.org/ dictionary/ english/work-at-home.

Cedefop (2016). Working at Sectorial Level. Retrieved November 18, 2018, from http://www. cedefop. europa.eu/en/publications-and-resources/publications/2217

Crosbie, T. \& Moore, J. (2009). Work-life Balance and Working from Home. Social Policy and Society, 3.

Eurofound (2015). New Forms of Employment. Retrieved November 12, 2019, https://www. eurofound.europa.eu/publications/report/2015/working-conditions-labour-market/new-formsof-employment, p.138.

Eurofound (2017). $6^{\text {th }}$ European Working Conditions Survey. Retrieved November 12, 2019, from https://www.eurofound.europa.eu/sites/default/files/ef publication/field ef document/ef1741 en.pdf.

European Commission (2016). ICT for work: Digital skills in the workplace. Retrieved April 12, 2018, from https://ec.europa.eu/digital-single-market/en/news/ict-work-digital-skills-workplace.

European Commission (2018). The Digital Skills and Jobs Coalition in a nutshell. Retrieved February 19, 2020, from https://ec.europa.eu/digital-single-market/en/news/digital-skills-and-jobs-coalition-nutshell.

European Commission. Europe 2020 Strategy. Retrieved April 17, 2020, from https://ec.europa.eu/ digitalsingle-market/en/europe-2020-strategy.

Eurostat. Enterprises that provided training to develop/upgrade ICT skills of their personnel. Retrieved May 3, 2020, from http://appsso.eurostat.ec.europa.eu/nui/show.do?dataset $=$ isoc ske ittn2\&lang=en.

Eurostat. Percentage of employed adults working at home by sex, age groups, number of children and age of youngest child. Retrieved October 9, 2019, from http://appsso.eurostat.eceuropa.eu/ nui/show.do?dataset=lfst hhwahchi\&lang=en.

Fried, J. \& Hansson, D.H. (2013). Remote: biroul este optional. Bucharest: Publica.

McCrindle Research. Working From Home: The Benefits and the Costs. Retrieved November 18, 2019, https://mccrindle.com.au/wp-content/uploads/2018/04/Working-from-Home The-Benefitsand-the-Cost McCrindle-Research.pdf.

Nickson, D \& Siddons, S. (2004). Remote Working. Linking People and Organization. Oxford: Elsevier Butterworth Heinemann.

OECD (2016). New Skills for the Digital Economy. Measuring the Demand and Supply of ICT Skills at Work. Retrieved November 13, 2019, from https://www.oecd-ilibrary. org/docserver/5jlwnkm2fc9xen.pdf?expires $=1542120697 \& \mathrm{id}=\mathrm{id} \&$ accname $=$ guest $\quad$ \&checksum $=\mathrm{C} 888 \mathrm{~A} 297 \mathrm{BD} \quad$ BD 1CF0F11DE2E4869A1D6689.

OECD (2016). Skills for a Digital World. Retrieved March 16, 2020, from https://www.oecd. org Lels/emp/Skills-for-a-Digital-World.pdf.

Strategy Analytics. Global mobile workforce forecast update 2016-2022. Retrieved February 19, 2020, from https://www.strategyanalytics.com/access-services/enterprise/mobile-workforce/market data/report-detail/global-mobile-workforce-forecast-update-2016-2022.

Timsal, A. \& Awais, M. (2016). Flexibility or ethical dilemma: an overview of the work from home policies in modern organizations around the world. Human Resource Management International Digest, Vol.24, pp.12-15.

World Economic Forum. The Future of Jobs Report 2018. Retrieved March 12, 2020, from https:// www.weforum.org/reports/the-future-of-jobs-report-2018. 